American J. of Engineering and Applied Sciences 4 (1): 1-9, 2011

ISSN 1941-7020

(C) 2010 Science Publications

\title{
High Rate-Dependent Interaction Diagrams for Reinforced Concrete Columns
}

\author{
${ }^{1}$ Taher Abu-Lebdeh, ${ }^{1}$ Sameer Hamoush, ${ }^{1}$ Wonchang Choi and ${ }^{2}$ Moayyad Al Nasra \\ ${ }^{1}$ Department of Civil, Architectural and Environmental Engineering, \\ North Carolina A and T State University, NC 27411, Greensboro, USA \\ ${ }^{2}$ Department of Engineering Technology, West Virginia University, \\ Institute of Technology, Montgomery, WV 25136, USA
}

\begin{abstract}
Problem statement: There is a need to better understand the rate dependence behavior of reinforced concrete structures in order to improve their response to impact and blast loads. Analysis and design of reinforced concrete structures subjected to seismic loadings has been recommended in many FEMA guidelines. However, reevaluation of design becomes extremely important in cases where large deformations are expected such as blast and impact resistant. Approach: This study presents a numerical model to evaluate reinforced concrete columns submitted to high strain rates expected for seismic, impact and blast loadings. The model utilizes dynamic stress-strain response and considers the effect of strain rate on concrete strength; strain at peak stress; yield and ultimate strength of steel; and slope of the softening portion of the stress-strain curve. Results: Results are presented in the form of interaction diagrams and compared with the available analytical and experimental results. Comparison with available data shows that the proposed model can give consistent prediction of the dynamic behavior of reinforced concrete columns. Conclusion/Recommendations: The established interaction diagrams may be used to design columns to withstand high velocity impact loads. Also, knowledge gained can be used to improve dynamic behavioral models and computer-aided analysis and design of reinforced concrete columns subjected to severe blast loadings.
\end{abstract}

Key words: High strain rate, interaction diagrams, stress-strain curves, Dynamic Increase Factor (DIF), axial-flexural strength, reinforced concrete columns, analytical model, velocity impact loads, analysis and design, dynamic stress-strain, different strain rates

\section{INTRODUCTION}

Analysis and design of reinforced concrete structures subjected to seismic loadings has been recommended in many building codes. However, high velocity impact loads resulted from blast are different. These loads are applied over a significantly shorter period of time than seismic loads. Thus, material strain rate effects become critical and must be accounted for in predicting columns performance for short duration loadings such as impact and blast loadings. Many experimental research results were reported in the area of compressive and tensile strength of concrete at different strain rates (Abu-Lebdeh et al., 2010; Ravichandran et al., 2009; Kotsovos, 1983). A selection of the commonly published results is also reported by Saravanan et al., 2010; Bischoff and Perry, 1991; and Malvar and Crawford (1998) as presented in Fig. 1 and and Fig. 2. Analyzing these two figures, it may be noticed that for both compressive (Fig. 1) and tensile loading (Fig. 2), there exist two intervals with different strain rates. For concrete in compression (Fig. 1) the first mode corresponds to a range of variations of strain rate ranging between $\dot{\varepsilon}=10-6 \sec ^{-1}$ and $\dot{\varepsilon}<10 \mathrm{sec}^{-1}$ leading to 1.5 times increase of the resistance in compression. The second mode for which the strain rate ranges from $\dot{\varepsilon}>10 \mathrm{sec}^{-1}$ to $\dot{\varepsilon}=103 \mathrm{sec}^{-1}$ allows to multiply by four where the resistance of the concrete is considered to be of structural origin. A model for strain rate dependence of concrete in tension and compression is presented in the Committee Euro-International Concrete (1993) Model Code 1990. In this model, the change in a moderate dynamic increase factor into the more dramatic one is set to a strain rate of $30 \mathrm{sec}^{-1}$. Many experimental and analytical research results were reported in the area of dynamic stress-strain response of reinforced concrete members under monotonically increasing loading (Scott et al., 1982; Grote et al., 2001; Ngo et al., 2007; Masti et al., 2008). Scott et al. (1982) conducted experimental and analytical investigations on the behavior of short reinforced concrete columns subjected to compression at low strain rates, $\dot{\varepsilon}$, that are ranging

Corresponding Author: Taher Abu-Lebdeh, Department of Civil, Architectural and Environmental Engineering, North Carolina A\&T State University, 1601 E. Market Street, NC 27411, Greensboro Tel: (336) 334-7575 ext. 664 Fax: (336) 334-7126 
Am. J. Engg. \& Applied Sci., 4 (1): 1-9, 2011

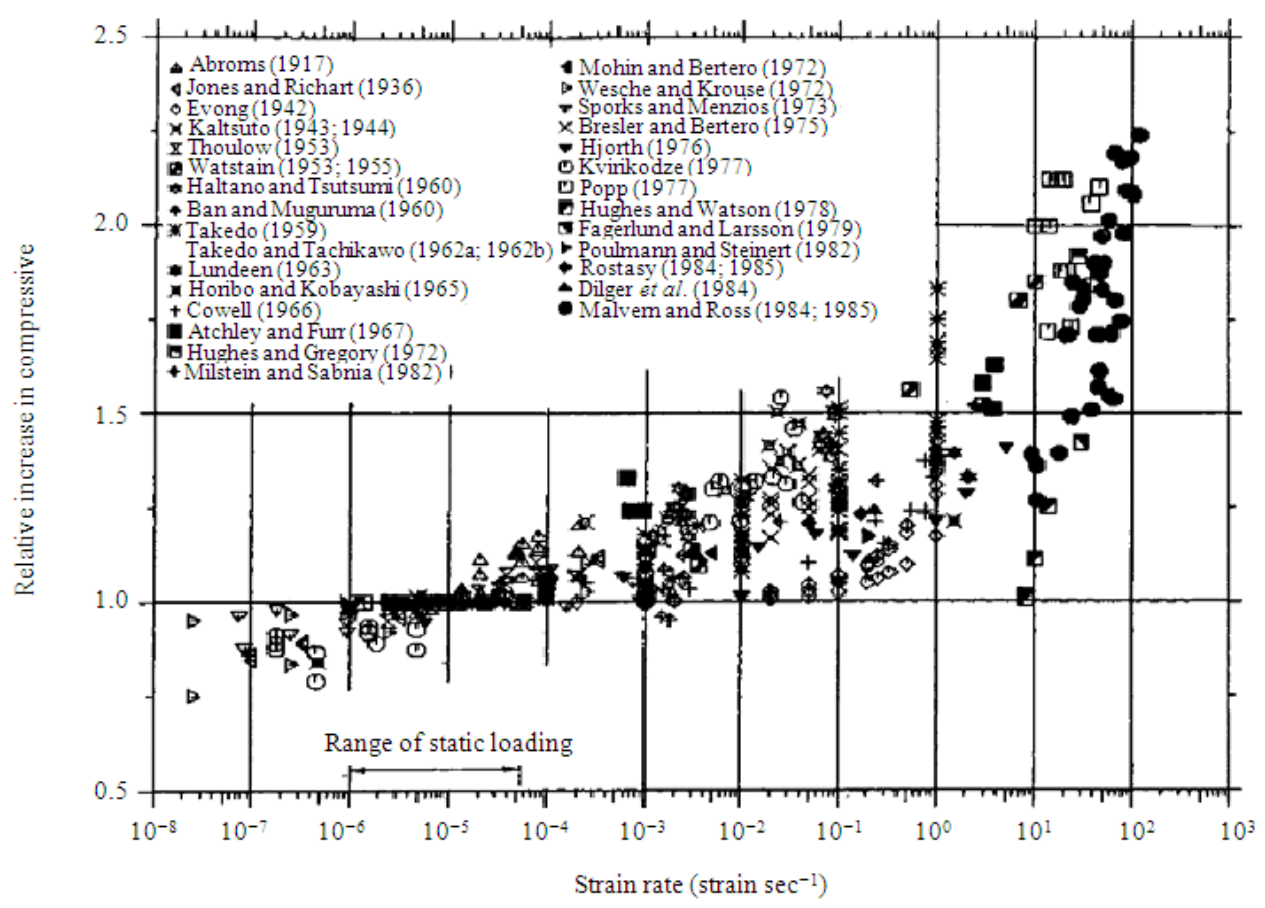

Fig. 1: Strain rate effects on the concrete compressive strength (Bischoff and Perry, 1991)

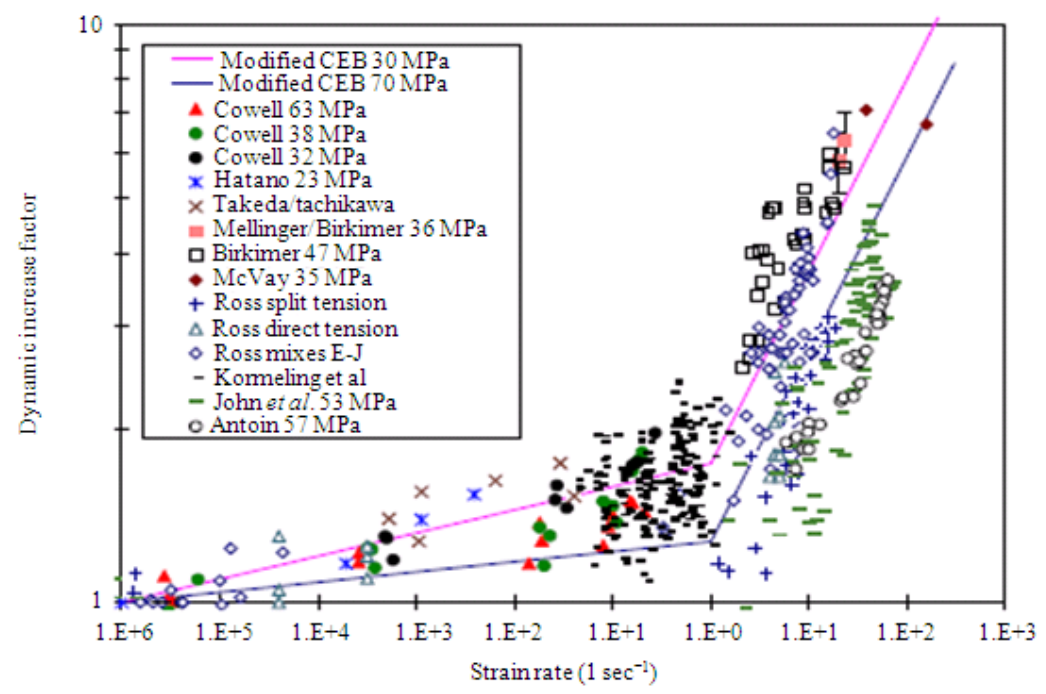

Fig. 2: Strain rate effects on the concrete tensile strength (Malvar and Crawford, 1998)

from $3.3 \times 10-6 \mathrm{sec}^{-1}$ (static loading) to $0.0167 \mathrm{sec}^{-1}$ (seismic loading). Their results are shown in Fig. 3. Although the experimental results of Scot et al. show the strain rate effect on stiffness before the peak, their analytical model appears to ignore this effect. Urgessa, 2009 investigated composite hardened walls subjected to blast Loads and Zaidi et al., 2010 develop an empirical prediction formula for penetration of hard missile into Concrete Targets. Grote et al. (2001) conducted Split Hopkinson Pressure Bar (SHPB) experiments which involve strain rates between 250 and $1700 \mathrm{sec}^{-1}$. They reported that the load-carrying capacity of the concrete increases significantly with strain rate and hydrostatic pressure. Ngo et al., 2007 studied stress-strain curves of concrete subjected to high strain rates, $\dot{\varepsilon}$, ranging from $30 \times 10-6 \mathrm{sec}^{-1}$ (quasi- 
static strain rate) to $264 \mathrm{sec}^{-1}$. They also show the experimental work of Gary and co-worker on the stressstrain curves of concrete at very high strain rates ranging from static loading to $700 \mathrm{sec}^{-1}$. Nagaradjane et al., 2009; Nagaradjane, et al., 2009; and Soroushian and Obaseki, 1986 investigated the strain rate effects on the axial-flexural strength of reinforced concrete sections. Parviz reported an average of $25 \%$ increase in axial-flexural capacity of rectangular sections under strain rate of $0.5 \mathrm{sec}^{-1}$ over the corresponding capacity under quasi-static strain rates.

\section{MATERIALS AND METHODS}

This study deals with the response modeling of concrete under high rate dynamic loadings. The model utilizes dynamic stress-strain response and capable of capturing the important features of the concrete material submitted to high strain rates. It accounts for the Dynamic Increase Factor (DIF) of concrete, which is the ratio of the dynamic strength to the static strength, ultimate strength of concrete and its corresponding dynamic strain. The DIF of concrete can be as high as 4 in compression and up to 6 in tension for strain rates in the range of 102-103 $\mathrm{sec}^{-1}$ (Sezen and Moehle, 2006). Based on experimental and analytical data reported by different researchers (Bischoff and Perry, 1991; CEB-FIP, 1993; Ngo et al., 2007; Saravanan et al., 2010; Abu-Lebdeh et al., 2010) the proposed strength increase factor ( $k_{d}$ or DIF) can be presented as indicated in Eq. 1 and 2 and shown in Fig. 4 and 5:

$\mathrm{k}_{\mathrm{d}}=\left(\frac{\dot{\varepsilon}}{\dot{\varepsilon}_{\mathrm{s}}}\right)^{\mathrm{a}}$ for $\dot{\varepsilon}_{\mathrm{s}} \leq \dot{\varepsilon} \leq 501 / \mathrm{s}$

$\mathrm{k}_{\mathrm{d}}=\beta\left(\frac{\dot{\varepsilon}}{\dot{\varepsilon}_{\mathrm{s}}}\right)^{036}$ for $\dot{\varepsilon}>501 / \mathrm{s}$

Where:

$\mathrm{k}_{\mathrm{d}}=$ Dynamic increase factor for concrete

$\dot{\varepsilon}=$ Strain rate $\left(1 \sec ^{-1}\right)$

$\dot{\varepsilon}_{\mathrm{s}}=5 \times 10-51 \mathrm{sec}^{-1}$ (quasi-static strain rate)

$\alpha=0.228\left(\mathrm{f}_{\mathrm{c}}^{\prime}\right)^{-0.7}$

$\beta=0.224\left(\mathrm{f}_{\mathrm{c}}^{\prime}\right)^{-0.28}$

$\mathrm{f}_{\mathrm{c}}^{\prime}=$ Concrete static compressive strength in MPa (145 psi)

Dynamic properties of reinforcing steel: Both the yield and ultimate stresses of reinforcing bars increase with an increase in strain rate, however, the ultimate stress increase is less significant than that of yield stress. Malvar (1998) studied the effects of high strain rates on strength enhancement of steel reinforcing bars.

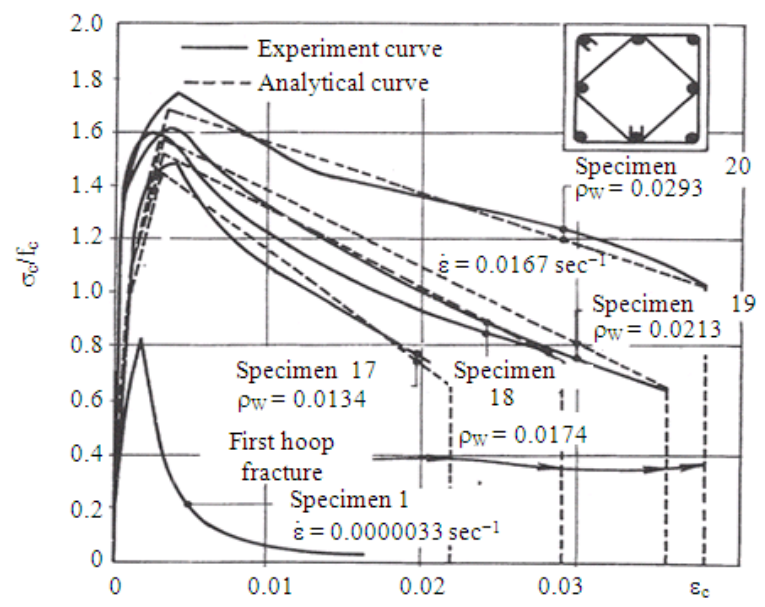

Fig. 3: Stress-strain diagrams for reinforced concrete specimens submitted to failure at low strain rates (Scott et al.)

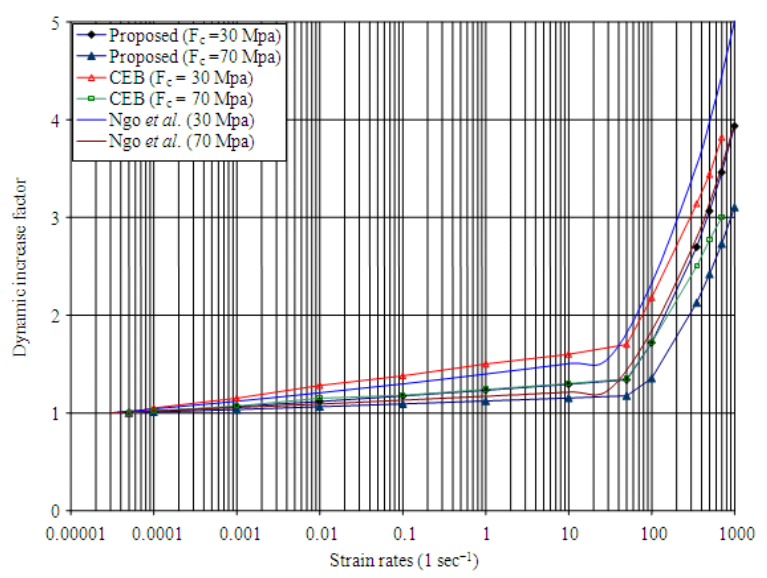

Fig. 4: Dynamic Increase Factor of concrete $(1 \mathrm{Mpa}=$ $145 \mathrm{psi})$

The strength enhancement was described in terms of the Dynamic Increase Factor (DIF) which can be evaluated for different steel grades and for yield stresses between 42 and $103 \mathrm{ksi}$ (290 and $710 \mathrm{MPa}$ ). He concluded that the Dynamic Increase Factor depends on the grade of steel and that the DIF for both yield and ultimate stress is inversely related to the yield stress itself. In the present study, the experimental data reported by different researchers and summarized by Malvar (1998) is used to formulate the DIF for both yield and ultimate stress. It was noticed that the date can be approximated by a straight line when $\log (\mathrm{DIF})$ versus $\log (\dot{\varepsilon})$ plot is used. The logarithm straight line equation is derived to formulate the proposed DIF as given in Eq. 3 and 4 for both yield and ultimate stress, respectively: 
Am. J. Engg. \& Applied Sci., 4 (1): 1-9, 2011

$$
\begin{aligned}
& \mathrm{k}_{\mathrm{y}}(1+10 \gamma)(\dot{\varepsilon})^{\mathrm{y}} \\
& \mathrm{k}_{\mathrm{u}}(1+10 \gamma)(\dot{\varepsilon})^{\lambda}
\end{aligned}
$$

Where:

$$
\begin{aligned}
\mathrm{K}_{\mathrm{y}}, \mathrm{k}_{\mathrm{u}}= & \text { Dynamic increase factor for steel yield stress } \\
& \text { and ultimate stress respectively } \\
\gamma= & 0.043 \text { and } 0.037 \text { for grades } 40 \text { and } 60 \\
& \text { respectively } \\
\lambda= & 0.025 \text { and } 0.013 \text { for grades } 40 \text { and } 60 \\
& \text { respectively }
\end{aligned}
$$

Stress-strain relationship of concrete under highstrain rates: The dynamic stress-strain relationship can be established for a given strain-rate. To accurately predict the stress-strain behavior of concrete under high strain rate, the model should consider the following factors: (1) concrete strength at a given strain rate, (2) strain at peak stress and (3) softening slope of the descending branch. Several concrete models have been proposed based on existing experimental evidence. Kent and Park (1971) have proposed the stress-strain curve in Fig. 6 for concrete confined by rectangular hoops. The ascending part of the curve is represented by a second-degree parabola and assumes that the maximum stress reached by the concrete is the cylinder strength $f_{c}^{\prime}$. The parameter $Z$ in the curve defines the slope of the descending portion. This slope is specified by the strain at stress of $0.5 f_{c}^{\prime}$. In region CD (Fig. 6), the equation $f_{c}=0.2 f_{c}^{\prime}$ accounts for the ability of concrete to sustain some stresses at very large strains. Although, their model combines many of the features of the previously proposed curves, it is not applicable for dynamic loadings. On the basis of the Kent and Park (1971) model, Scott et al. (1982) developed a strain-rate dependent model for confined concrete and included the effect of strain rates on the dynamic properties of the stress-strain relationship. The Scott model was based on a relatively low strain rate data ranging from a quasi-static rate of $3.3 \times 10^{-6}-16.7 \times 10^{-3} \mathrm{sec}^{-1}$. Based on calibration of Grote et al. (2001) experimental data which involved high velocity impact tests using Hopkinson Bar apparatus, the authors revised Kent and Park and Scott models to include the effect of very high strain rates on the stress-strain relations. A new strainrate dependent model is proposed herein for concrete under impact and blast loadings. It considers the effect of strain rate on concrete strength; strain at peak stress; and slope of the softening portion of the stress-strain curve. The proposed model is described by Eq. 5-9 and is compared with the available experimental and analytical results shown in Fig. 7 and 8: $\mathrm{f}_{\mathrm{c}}=\mathrm{k}_{\mathrm{d}} \mathrm{f}_{\mathrm{c}}^{\prime}\left[\frac{2 \varepsilon}{\varepsilon_{\mathrm{dc}}}-\left(\frac{\varepsilon}{\varepsilon_{\mathrm{dc}}}\right)^{2}\right]$ for $\varepsilon \leq \varepsilon_{\mathrm{dc}}$

$\mathrm{f}_{\mathrm{c}}=\mathrm{k}_{\mathrm{d}} \mathrm{f}_{\mathrm{c}}^{\prime}-\mathrm{Z}_{\mathrm{d}}\left(\varepsilon-\varepsilon_{\mathrm{dc}}\right)$ for $\varepsilon>\varepsilon_{\mathrm{dc}}$

The peak stress, $f_{c}^{\prime}$ in Kent and Park model (Fig. 6) increases to $f_{c}^{\prime}$ to include the effect of high strain rate. The strain at peak stress is also increased to $\varepsilon_{\mathrm{dc}}$ which is strain-rate dependent, as shown in Eq. 7:

$\varepsilon_{\mathrm{dc}}=1.08 \mathrm{e}^{(0.002 \varepsilon)} \varepsilon_{\mathrm{c}}$

Where:

$\varepsilon_{\mathrm{dc}}=$ The dynamic strain at peak stress

$\varepsilon_{\mathrm{c}}=$ The static strain $=1.75 \mathrm{f}_{\mathrm{c}}^{\prime} / \mathrm{E}_{\mathrm{C}}$

$\mathrm{E}_{\mathrm{c}}=$ The modulus of elasticity of concrete

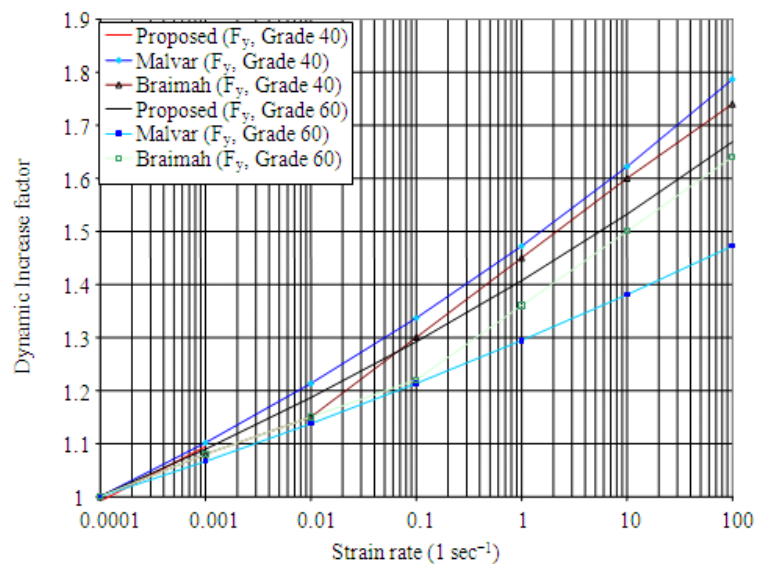

Fig. 5: Dynamic Increase Factor for yield stress of reinforcing steel

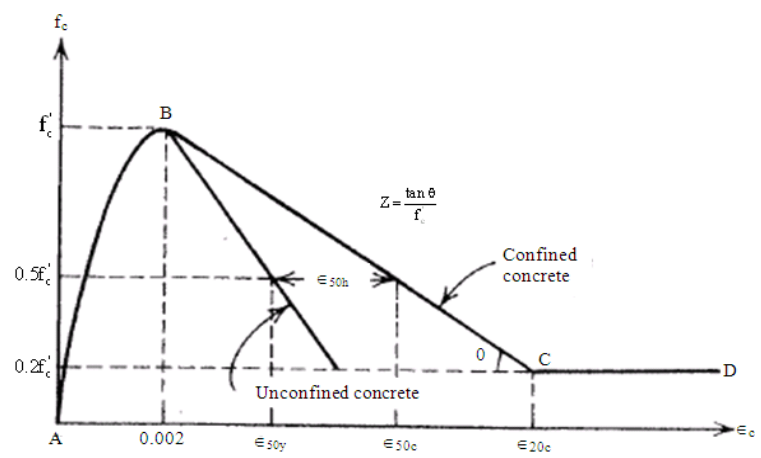

Fig. 6: Kent and Park Model for concrete under static loading 
Am. J. Engg. \& Applied Sci., 4 (1): 1-9, 2011

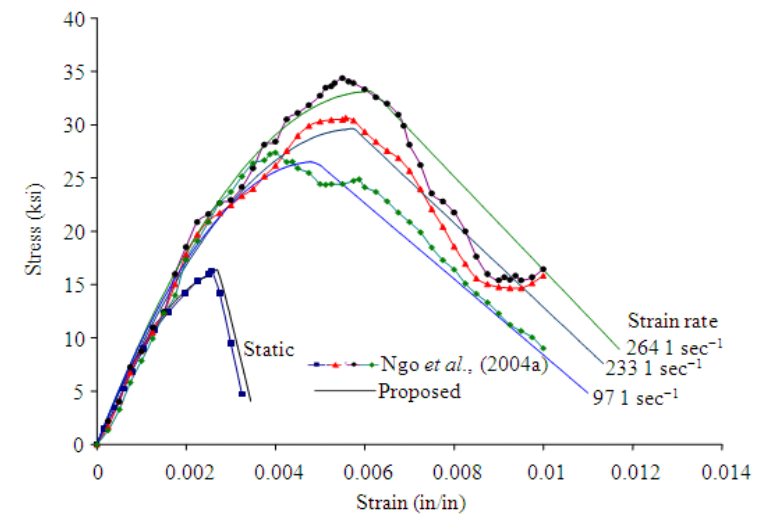

Fig. 7: Stress-strain curves of concrete at different strain rates

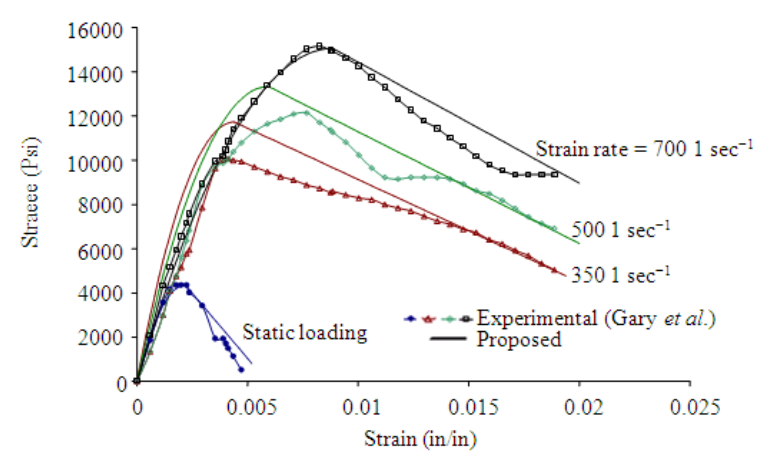

Fig. 8: Stress-strain curves of concrete at high strain rates

The equation for the linear descending portion of the stress-strain curve (Eq. 6) is given as a function of the dynamic slope, $Z_{d}$. This softening slope is determined based on the available experimental results (Grote et al., 2001; Ravichandran et al., 2009) and proposed as:

$$
\mathrm{Z}_{\mathrm{d}}=\frac{6.825\left(\mathrm{f}_{\mathrm{c}}^{\prime}\right)^{2} \mathrm{k}_{\mathrm{d}}\left(\dot{\varepsilon} / \dot{\dot{\varepsilon}}_{\mathrm{s}}\right)^{-0.122}}{0.007\left(\mathrm{f}_{\mathrm{c}}^{\prime}\right)^{-0.231}+\varepsilon_{\mathrm{c}}}
$$

The proposed model assumes that the maximum strain, $\varepsilon_{\max }$ is reached when its corresponding stress level reaches $f_{d c}$ (Similar to $f_{c}=0.2 f_{c}^{\prime}$ in Kent and park model for unconfined concrete (Fig. 6)). The proposed maximum strain and its corresponding stress are also strain-rate dependent as shown in Eq. 9 and 10. Table 1 summarizes the parameters of the proposed model with their corresponding values in Kent and park model:

$\varepsilon_{\max }=\frac{k_{d} f_{c}^{\prime}-f_{d c}}{Z_{d}}+\varepsilon_{d c}$
Table 1: Parameters of the proposed model

\begin{tabular}{llll}
\hline Parameter & Kent model (Fig. 6) & \multicolumn{2}{l}{ Proposed model } \\
\hline Peak stress & $\mathrm{f}_{\mathrm{c}}$ & $\mathrm{k}_{\mathrm{d}} \mathrm{f}_{\mathrm{c}}$ & (Eq. 1 and2) \\
Strain at peak stress & 0.002 & $\varepsilon_{\mathrm{dc}}$ & (Eq. 7) \\
Maximum strain & $\varepsilon_{20 \mathrm{u}}$ & $\varepsilon_{\max }$ & (Eq. 9) \\
stress at maximum strain & $0.2 \mathrm{f}_{\mathrm{c}}$ & $\mathrm{f}_{\mathrm{dc}}$ & (Eq. 10) \\
Softening slope & $\mathrm{Z}$ & $\mathrm{Z}_{\mathrm{d}}$ & (Eq. 8) \\
\hline
\end{tabular}

$\mathrm{f}_{\mathrm{dc}}=0.15 \mathrm{k}_{\mathrm{d}}^{2} \mathrm{f}_{\mathrm{c}}^{\prime}$

Strain rate-dependent axial-flexural model: The main goal of this study is to investigate the strain rate effects on the behavior of reinforced concrete columns subjected to different strain rates ranging from quasistatic loading to $700 \mathrm{sec}^{-1}$ (expected for impact and blast loadings) to develop reinforced concrete constitutive model capable of producing interaction diagrams for dynamic loadings. The proposed model is derived on the basis of the modeled dynamic stressstrain relationships for concrete and steel and on the assumptions that the strain distribution is linear; the deformed section remains plane; and perfect bond between the steel and concrete. The axial load and moment carrying capacities of the reinforced concrete sections are determined from the requirements of strain compatibility and equilibrium of forces by varying the location of the neutral axis. The curvature is the compressive strain divided by the depth of the neutral axis.

Effect of strain-rate on ductility: Ductility is a desirable feature of any structural design as it safeguards a structure against unpredicted overloading and/or load reversal. It is generally measured by the ductility factor which is the ratio of the ultimate deformation to that at the first yielding of steel reinforcement. It can be evaluated at the structure level (displacement ductility), member level (rotational ductility) and at the cross-section level (curvature ductility). In the present study, ductility factor is defined as:

$\mathrm{DF}=\frac{\phi_{\mathrm{u}}}{\phi_{\mathrm{y}}}$

Where:

$\phi_{\mathrm{y}}=$ The curvature at the initial yielding of the steel

$\phi_{\mathrm{u}}=$ The curvature corresponding to a moment equal to $80 \%$ of $\mathrm{Mu}$

This is because the maximum usable deformation is the deformation at which the resistance decays to $80 \%$ of resistance at ultimate. 


\section{RESULTS}

Stress-Strain relationship of concrete under highstrain rates: Comparing the analytical and experimental data (Fig. 7 and 8), the proposed model can give consistent prediction of the dynamic behavior of concrete materials. Figure 7 shows comparison between the proposed stress-strain relationship and $\mathrm{Ngo}$ et al. (2007) for strain rates ranging from static loading to $264 \mathrm{sec}^{-1}$. The effect of very high strain rates (up to $700 \mathrm{sec}^{-1}$ ) is shown in Fig. 8 and compared with the experimental results of Gary et al reported by Ngo et al. (2007). As shown in these figures, peak stress and its corresponding strain increase with strain rates. Moreover, the elastic modulus increases slightly. This moderate enhancement of the elastic modulus may be due to the decrease in internal microcracking at a given stress level with an increasing strain rate.

Strain rate-dependent axial-flexural model: Results of the proposed model are presented in the form of interaction diagrams for different strain rates. Figure 9 shows the proposed interaction diagrams that were obtained for rectangular concrete sections using the method described earlier. A comparison with the experimental and theoretical strain rate-dependent interaction diagram is shown in Fig. 9a and b. It should be mentioned that the theoretical model proposed by Parviz and Obaseki follows the fiber modeling concept to compute the axial and flexural resistance of a reinforced concrete section at low strain rate (up to 0.5 $\left.\mathrm{sec}^{-1}\right)$. In the present study, the approximate ranges of the expected strain rates for different loading conditions were used to produce the interaction diagrams shown in Fig. 10a, b. The quasi-static rate is given as $\dot{\varepsilon}=5 \times 10^{-5}$ $\sec ^{-1}$ and compared with the ACI formulation, while $\dot{\varepsilon}$ of 0.05 and $0.5 \mathrm{sec}^{-1}$ were selected for strain rates expected under seismic loading, $\dot{\varepsilon}$ of 5, 50 and 100 $\mathrm{sec}^{-1}$ for impact loadings and $\dot{\varepsilon}$ of 350,500 and 700 $\mathrm{sec}^{-1}$ for high velocity impact resulted from blast loadings. The ACI diagram shown in Fig.10 is based on quasi-static tests in which the rate of loading is of the order of $0.00005 \mathrm{sec}^{-1}$. Figure 10 indicates that increasing the strain rate significantly increases the axial-flexural capacity of the concrete section.

Influence of the longitudinal steel ratio: Figure 11 shows the influence of reinforcement ratio at different strain rates for reinforced concrete sections with the same geometry and same steel positions, but with different reinforcement ratios of 1,3 and $5 \%$ respectively.

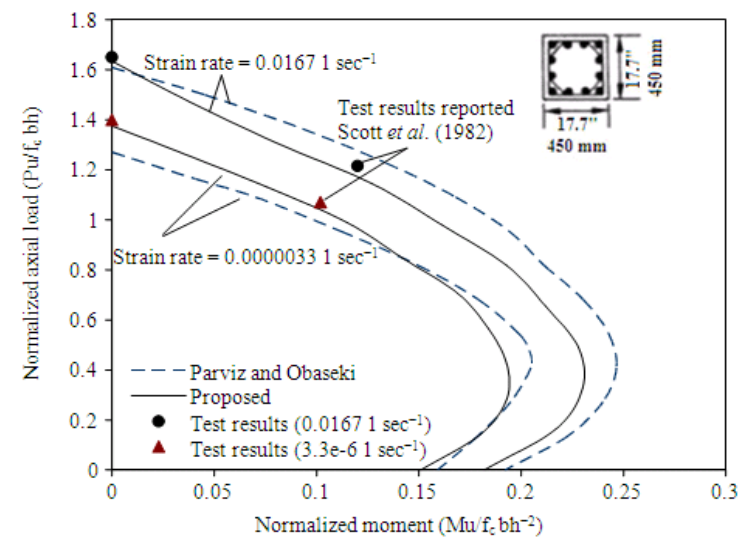

(a)

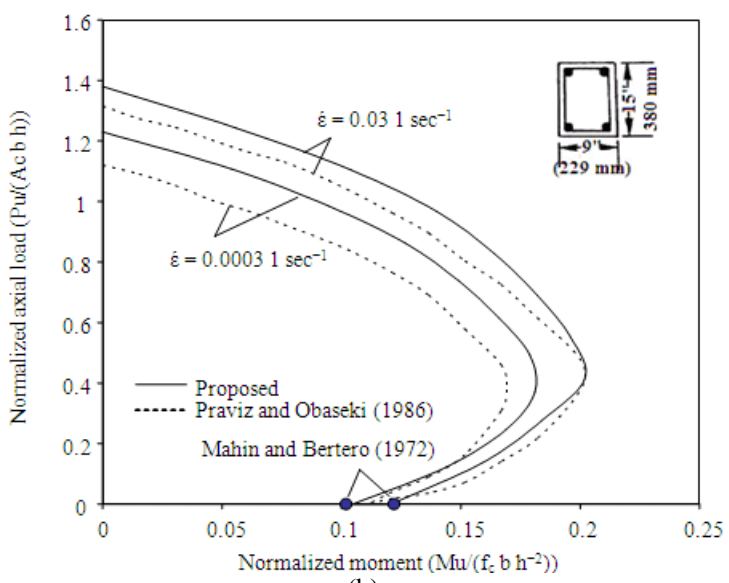

(b)

Fig. 9: Comparison of the proposed strain ratedependent interaction diagram with the experimental and theoretical results

Influence of the longitudinal steel position: Figure 12 compares the interaction diagrams of a column section at four different strain rates $0.00005 / \mathrm{s}, 0.5 / \mathrm{s}, 10 / \mathrm{s}$ and 250/s representing loading conditions from static to blast loadings. Three different " $\gamma$ " values of $0.6,0.7$ and 0.8 were used. " $\gamma$ " is defined as the ratio of the center to center spacing of the extreme steel layers to the height of the section.

Effect of strain-rate on ductility: The proposed strainrate dependent model for concrete is used herein to investigate the effects of high strain-rate on the flexural capacity and ductility of reinforced concrete members (Fig. 13 and 14). The axial load and moment carrying capacities are determined from the force equilibrium and the curvature is the compressive strain divided by the depth of the neutral axis. Figure 14 shows the Ductility Factor (DF) with varying strain rates for three different steel positions. The ductility factor is calculated at axial load of $40 \%$ of the axial load carrying capacity. 
Am. J. Engg. \& Applied Sci., 4 (1): 1-9, 2011

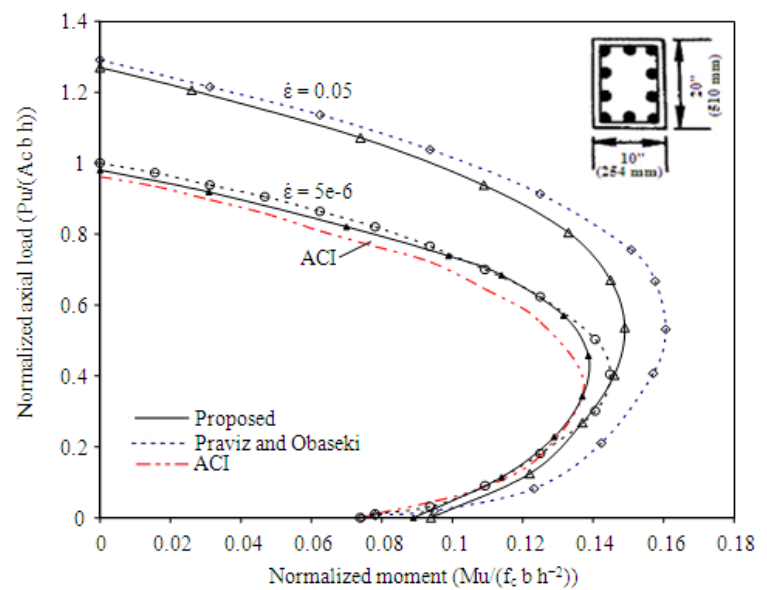

(a)

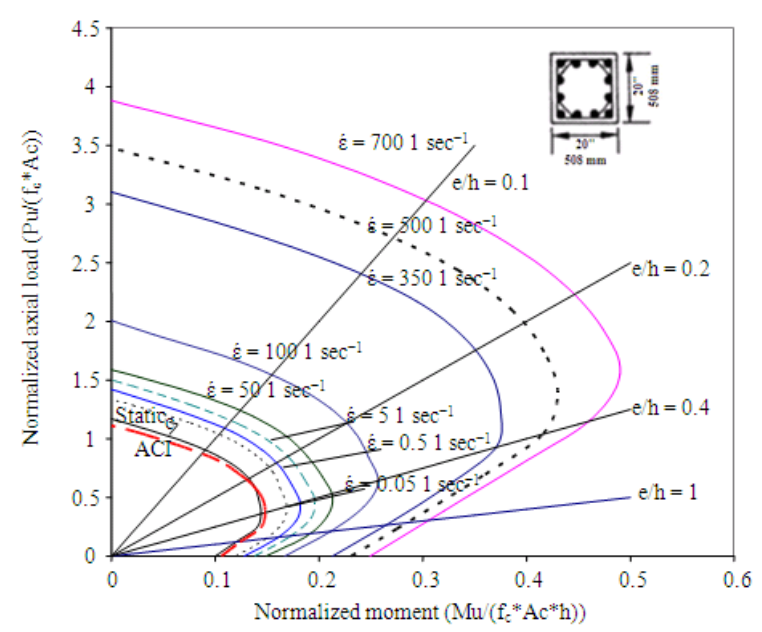

(b)

Fig. 10: Comparison of the proposed and the ACI interaction diagrams (reinforcement ratio, $\rho_{\mathrm{s}}$ $=1 \%$ ) (a) Low strain rate; (b) High strain rate

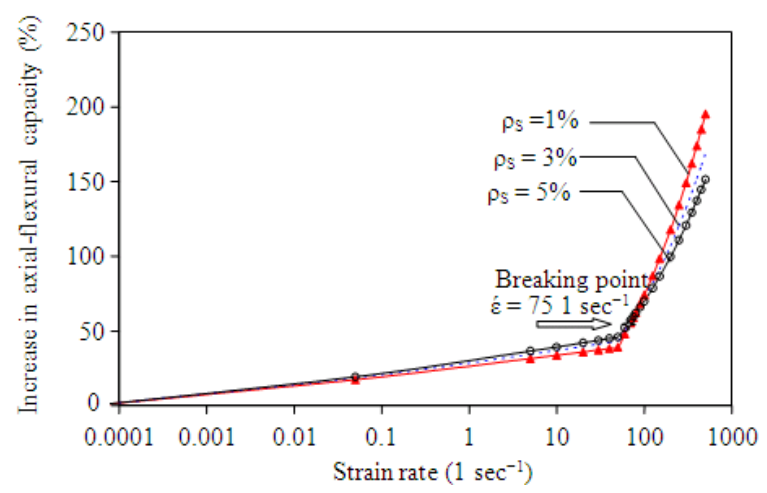

Fig. 11: Influence of reinforcement ratio on the strain rate effect

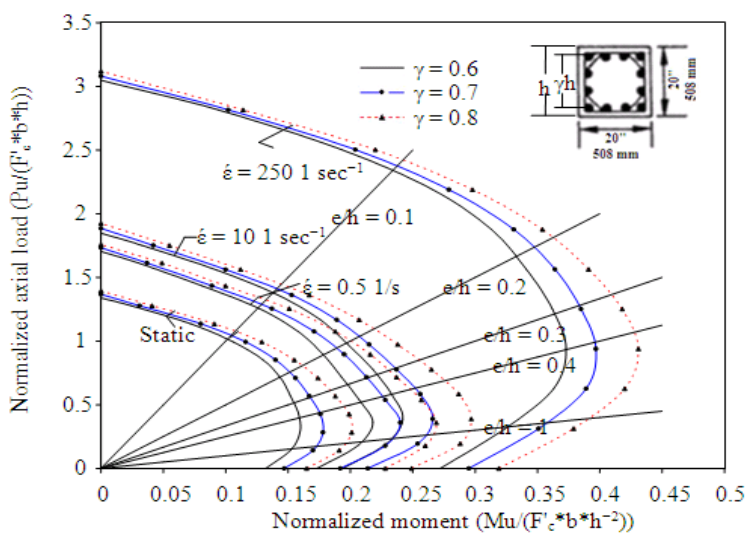

Fig. 12: Influence of reinforcement position on the strain rate effect

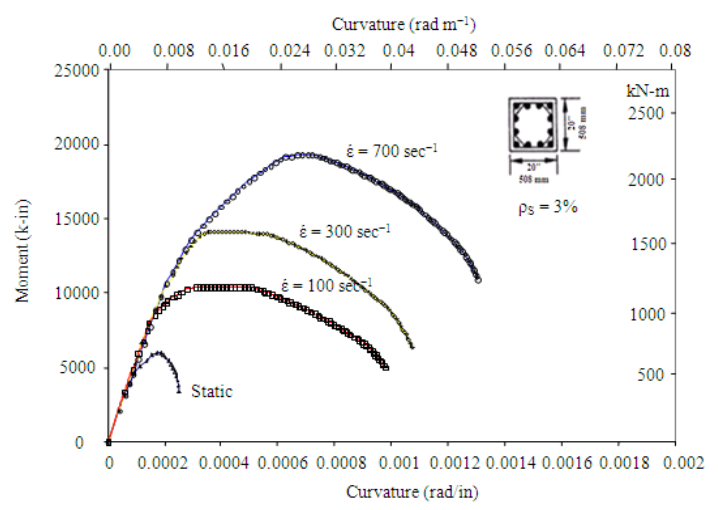

Fig. 13: M- $\Phi$ Curves of a cross-section of a column at different strain rates.

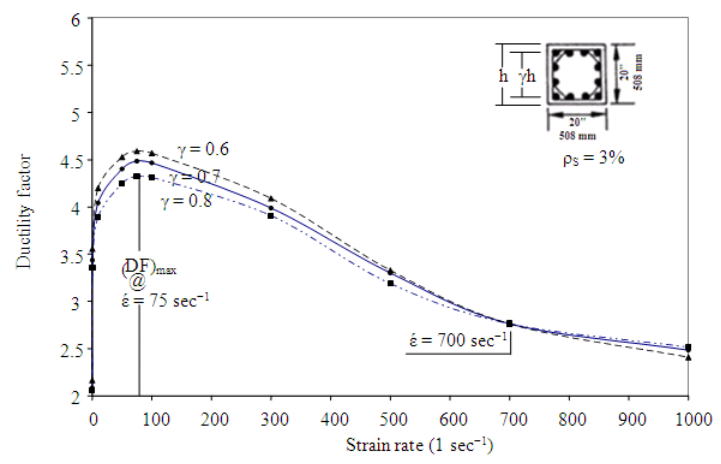

Fig. 14: Effect of strain rate and confinement on the ductility of concrete columns

\section{DISCUSSION}

Strain-rate dependent concrete model: Examining Eq. 1-2 and Fig. 4, we can distinguish two different intervals with different strain rate dependencies: the 
first interval corresponds to a range of variations of strain rate ranging between the quasi-static $\dot{\varepsilon}=5 \times 10^{-5}$ $\mathrm{sec}^{-1}$ and $\dot{\varepsilon}<50 \mathrm{sec}^{-1}$ leading to DIF of 1.35 and 1.17 for concrete strengths of $4350 \mathrm{psi}(30 \mathrm{MPa})$ and 10,150 psi (70 MPa) respectively. The increase in strength for this interval is moderate increase. Researchers agree on the explanation for such strength increase pertinent to a material viscosity (Rossi, 1991), that is viscous effects with free water in the micropores. The second interval for which the strain rate $\dot{\varepsilon}>50 \mathrm{sec}^{-1}$ up to $\dot{\varepsilon}=10^{3} \mathrm{sec}^{-1}$ allows to multiply by four the strength of the concrete. The increase in strength for this interval is sharp increase. Explanations for this behavior can mainly be ascribed to inertia effects and lateral confinement. When concrete cylinder is subjected to static compressive loading, it exhibits lateral expansion due to the effect of Poisson's ratio; also, the behavior will be affected by the propagation of microcracks. However, when subjected to rapid axial loading, the time available for initiation and propagation of microcracks will be reduced. Moreover, the material will not be able to expand in the radial direction at an instant due to inertial restraint. This lateral confinement will initially leave the specimen in a similar stress state as that of uniaxial strain with corresponding lateral stresses. Thus, result in a substantial increase in compressive strength.

Influence of the longitudinal steel ratio: It can be concluded from Fig. 11 that for strain rates ranging from quasi-static to $\dot{\varepsilon}=75 / \mathrm{s}$, the percent increase in axial-flexural capacities is not influenced by the longitudinal steel ratio. For the three ratios shown in Fig. 11, increasing the strain rate from $0.00005 / \mathrm{s}$ (static loading) to $\dot{\varepsilon}=75 / \mathrm{s}$ (breaking point) results in an average increase of $60 \%$ in axial-flexural capacity. However, for strain rates higher than $75 / \mathrm{s}$, the lower the steel ratio the higher the percent increase in axialflexural capacity. At high strain rate $(\dot{\varepsilon}=500 / \mathrm{s}$, for instance) compared to those capacities under static loading, it can be observed from Fig. 11 that the increase in axial-flexural strength may reach $195 \%$, $170 \%$ and $150 \%$ for reinforcement ratios of $1 \%, 3 \%$ and $5 \%$ respectively.

Influence of the longitudinal steel position: From Fig. 12, it can be observed that: for each strain rate, the average increase in axial-flexural capacity at e/h of 0.45 is 35,50 and $95 \%$ for $\gamma$ values of $0.6,0.7$ and 0.8 respectively. This increase in capacity with $\gamma$ may be due to the resulting increase in confinement.

Effect of strain-rate on ductility: As shown in Fig. 13 the flexural capacities of a reinforced concrete column were significantly increased due to the increase in yield strength of steel and compressive strength of concrete at high strain rate. Moreover, because the dynamic strain corresponding to compressive strength increases with strain rate, consequently, curvature and bending moment carrying capacity will increase. For the three steel positions (Fig. 14), the Ductility Factor (DF) increases with strain rate up to $75 \mathrm{sec}^{-1}$. This is because of the fact that as the strain rate increases, the compressive strength and the corresponding strain increase, hence both the flexural capacity and the curvature increase. Moreover, the ultimate strain of the concrete section increases, consequently, the tensile reinforcement steels undergo strain hardening range resulting in increase in the bending moment carrying capacity and the ductility. However, for strain rates higher than $75 \mathrm{sec}^{-1}$, the rate of increase of the curvature at first yielding of reinforcement is larger than that at the maximum curvature, resulting in decrease in the ductility factors.

\section{CONCLUSION}

Based on this study, the following conclusions may be drawn:

- Comparison with available test results shows that the proposed model can give consistent prediction of the dynamic behavior of concrete materials. However, for more accurate estimation of the P-M interaction diagrams, more strain rate-dependent experimental tests are needed

- A Dynamic Increase Factor (DIF) of 1.35 was determined for concrete at strain rates of $\dot{\varepsilon}=50 \mathrm{~s}^{-1}$. In the second interval, a factor of four is used for $\varepsilon$ $=10^{3} \mathrm{~s}^{-1}$

- Both the yield and ultimate stresses of reinforcing bars increase with an increase in strain rate. The ultimate strength increase is less significant than that of yield strength

- Increasing the strain rate significantly increases the axial-flexural capacity of the concrete section due to the significant increase in strength of concrete and steel reinforcing bars. Increasing the strain rate from $0.00005 / \mathrm{s}$ to $\dot{\varepsilon}=75 \mathrm{sec}^{-1}$ results in an average increase of $60 \%$ in axial-flexural capacity. For strain rates higher than $75 \mathrm{sec}^{-1}$, the increase in axial-flexural strength may reach $195 \%$

- The strain rate effect is influenced by the position of the longitudinal steel. Placement of steel closer to extreme compressive and tensile layer, increase the strain rate effects. For a typical concrete 
section, an average increase in axial-flexural capacity of 35,50 and $95 \%$ were determined for $\gamma$ values of $0.6,0.7$ and 0.8 respectively

- The proposed model assumes perfect bond between the steel and concrete, hence, it does not consider the strain rate effects on the rebar/concrete interface behavior. To better understand this behavior and its effect on the interaction diagrams, more high strain rate-dependent experimental tests are needed

\section{ACKNOWLEDGMENT}

The researchers would like to graciously thank the Defense Threat Reduction Agency (DTRA) for funding of this research.

\section{REFERENCES}

Abu-Lebdeh, T., S. Hamoush and B. Zornig, 2010. Rate effect on pullout behavior of steel fibers embedded in very-high strength concrete. Am. J. Eng. Applied Sci., 3: 454-463. DOI: 10.3844/ajeassp.2010.454.463

Bischoff, P.H. and S.H. Perry, 1991. Compressive behavior of concrete at high strain rates. Mater. Struct., 24: 425-450. DOI: 10.1007/BF02472016

Committee Euro-International Concrete, 1993. CEBFIP model code 1990: design code. 1st Edn., Thomas Telford, Switzerland, ISBN: 0727716964 pp: 437.

Grote, D.L., S.W. Park and M. Zhou, 2001. Dynamic behavior of concrete at high strain rates and pressures: Experimental characterization. Inter. J. Impact Eng., 25: 869-886. DOI: 10.1016/S0734743X(01)00020-3

Kent, D.C. and R. Park, 1971. Flexural members with confined concrete. J. Struct. Div. ASCE., 97: 1969-1990. http://cedb.asce.org/cgi/WWWdisplay.cgi?18246

Kotsovos, M.D., 1983. Effect of testing techniques on the post-ultimate behavior of concrete in compression. Mater. Struct., 16: 3-12. DOI: 10.1007/BF02474861

Malvar, L.J. and J.E. Crawford, 1998. Dynamic increase factors for concrete. Proceeding of the 28th Department of Defense Explosives Safety Seminar (DDESB), Aug. 18-20, ANSI Std, Orlando, pp: 1-18. http://www.dtic.mil/cgibin/GetTRDoc?Location=U2\&doc $=$ GetTRDoc.pdf $\& \mathrm{AD}=\mathrm{ADA} 500715$

Malvar, L.J., 1998. Review of static and dynamic properties of steel reinforcing bars. ACI Mate. J., 95: 609-616. http://tris.trb.org/view.aspx?id=542157
Masti, K., A.A.B. Maghsoudi and R. Rahgozar, 2008. Nonlinear models and experimental investigation of lifetime history of HSC flexural beams. Am. J. Applied Sci., 5: 248-262. DOI: 10.3844/ajassp.2008.248.262

Nagaradjane, V., P.N. Raghunath and K. Suguna, 2009. Reliability of axially loaded fibre-reinforcedpolymer confined reinforced concrete circular columns. Am. J. Eng. Applied Sci., 2: 31-38. DOI: 10.3844/ajeas.2009.31.38

Ngo, T., P. Mendis, A. Gupta and J. Ramsay, 2007. Blast loading and blast effects on structures-an overview. EJSE Int. J. Load. Struct., Special Issue: 76-91.

http://www.ejse.org/Archives/Fulltext/2007/Specia 1/200707.pdf

Ravichandran, A., K. Suguna and P.N. Ragunath, 2009. Strength modeling of high-strength concrete with hybrid fibre reinforcement. Am. J. Applied Sci., 6: 219-223. DOI: 10.3844/ajassp.2009.219.223

Rossi, P., 1991. A physical phenomenon which can explain the mechanical behavior of concrete under high strain rates. Mater. Struct., 24: 422-424. DOI: 10.1007/BF02472015

Saravanan, J., K. Suguna and P.N. Raghunath, 2010. Confined high strength concrete columns: An experimental study. Am. J. Eng. Applied Sci., 3: 133-137. DOI: 10.3844/ajeassp.2010.133.137

Scott, B.D., R. Park and M.J.N. Priestley, 1982. Stressstrain behavior of concrete confined by overlapping hoops at low and high strain rates. Struct. J. ACI., 79: 13-27. http://www.concrete.org/PUBS/JOURNALS/OLJD etails.asp?Home $=\mathrm{JP} \& \mathrm{ID}=10875$

Sezen, H. and J.P. Moehle, 2006. Seismic tests of concrete columns with light transverse reinforcement. ACI Struct. J., 103: 842-849. http://www.concrete.org/PUBS/JOURNALS/Abstr actDetails.asp? ID $=18236$

Soroushian, P. and K. Obaseki, 1986. Strain ratedependent interaction diagrams for reinforced concrete sections. ACI J., 83: 108-116. http://www.concrete.org/PUBS/JOURNALS/OLJD etails.asp?Home=JP\&ID=1751

Urgessa, G.S., 2009. Finite element analysis of composite hardened walls subjected to blast loads. Am. J. Eng. Applied Sci., 2: 804-811. DOI: 10.3844/ajeassp.2009.804.811

Zaidi, A.M.A., Q.B.A.I. Latif, I.A. Rahman and M.Y. Ismail, 2010. Development of empirical prediction formula for penetration of ogive nose hard missile into concrete targets. Am. J. Applied Sci., 7: 711-716. DOI: 10.3844/ajassp.2010.711.716 